\title{
Electrospun Sn Embedded in Carbon Nanofibers as an Anode for High-Performance Lithium-Ion Batteries
}

\author{
Da-Mi Kim, Young-Woo Lee, Si-Jin Kim, Min-Cheol Kim, Gyu-Ho Lee, Hui-Seon Choe, \\ Wansoo Huh and Kyung-Won Park* \\ Department of Chemical Engineering, Soongsil University, Seoul 156743, Republic of Korea \\ *E-mail: kwpark@ssu.ac.kr \\ doi: $10.20964 / 110441$
}

Received: 4 February 2016 / Accepted: 13 March 2016 / Published: 1 April 2016

\begin{abstract}
Well-defined composite electrodes have been known to have enhanced lithium ion reaction such as the capacity, stability, and cycling performance. We prepared the composite electrodes consisting of Sn nanoparticles and carbon nanofibers $(\mathrm{Sn} / \mathrm{CNF})$ as an anode material for high-performance lithium-ion batteries (LIBs) using electrospinning method and calcination process under nitrogen atmosphere. The as-prepared Sn/CNF showed metallic Sn nanoparticles uniformly embedded in the CNF as confirmed by X-ray diffraction (XRD), raman spectroscopy, X-ray photoelectron spectroscopy (XPS), fieldemission scanning electron microscopy (FE-SEM), energy-dispersive X-ray spectroscopy (EDX), and field-emission transmission electron microscopy (FE-TEM). The performance of the samples as an anode for LIBs was evaluated by charge-discharge and high rate curves, cyclic voltammograms (CVs), and electrochemical impedance spectroscopy using lithium coin cells. Compared to CNF-only, $\mathrm{Sn} / \mathrm{CNF}$ exhibited high specific capacity, improved stability, and excellent high rate cycling performance due to low transport resistance and high diffusion coefficient for lithium ions.
\end{abstract}

Keywords: composite materials; nanostructures; electrochemical properties

\section{FULL TEXT}

(C) 2016 The Authors. Published by ESG (www.electrochemsci.org). This article is an open access article distributed under the terms and conditions of the Creative Commons Attribution license (http://creativecommons.org/licenses/by/4.0/). 